\title{
La necesaria construcción de una democracia paritaria para el Derecho Privado: la igualdad de género en los consejos de administración de las sociedades cotizadas
}

\author{
The necessary construction of a paritary democracy \\ for Private Law: gender equality in the management \\ boards of listed companies
}

\author{
Sergio Martín GuARdAdo * \\ Personal Investigador en Formación \\ Departamento de Derecho Público General. Área de \\ Derecho Constitucional. Universidad de Salamanca \\ ORCID: 0000-0003-0116-5301
}

Recibido: 03/12/2019

Aceptado: 08/04/2020

doi: https://doi.org/10.20318/femeris.2020.5391

\begin{abstract}
Resumen. El trabajo que se presenta trata de buscar argumentos en favor de extender la democracia paritaria, concepto surgido del Derecho Público, al ámbito social y económico. Sólo la equiparación igualitaria entre mujeres y hombres puede superar la vulneración de derechos humanos a que se está sometiendo a la mitad mayoritaria de la población y, lograr así, el aprovechamiento máximo de los conocimientos y aptitudes de la sociedad. Así pues, la idea es superar la infrarrepresentación femenina en los consejos de administración de las sociedades cotizadas, vinculando el papel de estas y su actuación en los mercados en relación con la toma de decisiones en el poder político, cada vez más sometidas directa o indirectamente al poder de los mercados. El desarrollo del Estado Social y Democrático de Derecho, más allá de lo público, puede materializar la igualdad efectiva entre mujeres y hombres, adoptando una concreta medida de acción positiva: sistema de cuotas. En definitiva, se presenta una justificación constitucional para la necesaria adopción de dichas políticas, formulando una democracia paritaria para el Derecho Privado y una revisión normativa a modo de lege ferenda.

Palabras clave: democracia paritaria, sociedades cotizadas, igualdad efectiva, cuotas, consejo de administración.
\end{abstract}

Abstract. The paper that is presented tries to find arguments in favor of the possibility of extending the paritary democracy, a concept that emerged from Public Law, to the social and economic field. Only material equal equality between women and men can overcome the violation of human rights to which they are submitting to the majority of the population and, thus, consider the maximum use of the knowledge and skills of society. Then, the idea is to overcome female underrepresentation in the boards of directors of listed companies, linking their role and their performance in the markets in relation to decision-making in political power, more

*martinguardado@usal.es 
and more directly or indirectly submitted To the power of the markets. The development of the Social and Democratic State of Law, beyond the public, can materialize effective equality between women and men, adopting a concrete measure of positive action: quota system. In short, a constitutional justification for the necessary adoption of these policies is presented, formulating a paritary democracy for Private Law and a normative revision as a lege ferenda. Keywords: paritary democracy, listed companies, material equality, quotes, management boards.

\section{Introducción}

La democracia paritaria, desde sus orígenes, ha sido un concepto tradicionalmente ligado al ámbito del Derecho Público. La idea que inspira la formulación del concepto no es otra que partir de la consideración de las mujeres no como un colectivo minoritario sometido a discriminación, sino como la mitad mayoritaria de la población que, al ser discriminada, determina la exclusión de la mitad de las inteligencias y capacidades potenciales de la humanidad (Sevilla Merino, 2003, p. 28). Su originaria formulación iba encaminada a posibilitar que las mujeres fueran titulares de un derecho fundamental de sufragio pasivo más allá del sufragio meramente activo, esto a partir de que las pretensiones del feminismo más significativo de la era contemporánea (el movimiento sufragista) encontraron una respuesta a las mismas, al reconocerse en muchos países el sufragio universal (Nuño Gómez, 2009). Y, por tanto, desde el origen, la democracia paritaria tiene una vinculación más estrecha con el principio de igualdad material que con el principio de no discriminación (Ventura Franch y García Campá, 2018, p. 56) ${ }^{1}$. La igualdad formal reconocida como derecho fundamental (art. $14 \mathrm{CE}$ ) debe alcanzar su plenitud y, la manera no es otra, que desarrollar políticas públicas que, en la práctica, instauren una sociedad más igualitaria, más democrática y, por tanto, más justa. Y, político pero también en el social y económico, desechar discriminaciones fundadas en el sexo o el género. La igualdad y la justicia social irrenunciables en el Estado Social y Democrático de Derecho (art. 1.1 CE): no hay democracia sin igualdad y no hay democracia sin igualdad entre mujeres y hombres.

Tanto la Organización de Naciones Unidas como la Unión Europea han experimentado una larga trayectoria en la producción de declaraciones y normas orientadas a lograr una participación equilibrada en los ámbitos de poder político y decisión pública. Es precisamente la Declaración de Atenas de 1992 (en el marco de una cumbre europea que adoptó la expresión "Mujeres en el Poder") la que expresa, por primera vez, el contenido necesario para apuntar una teoría de democracia paritaria. A nivel internacional, el interés por la democracia paritaria desemboca en la Declaración de Beijing de 1995 (IV Conferencia Mundial sobre la Mujer), también referida a los ámbitos de poder público. El concepto, se concretará después, en la idea de que la democracia plena y en igualdad

\footnotetext{
${ }^{1}$ Realmente, "el derecho a la igualdad efectiva de mujeres y hombres es a la teoría jurídica lo que la democracia paritaria es a la teoría política”, en tanto que el principio de igualdad material supone la búsqueda de la equiparación entre mujeres y hombres en la sociedad y el principio de no discriminación corrige situaciones concretas de subyugación por razón de sexo o género.
} 
entre mujeres y hombres sólo es posible a través de la consecución de una composición y representación equilibrada entre los sexos. Esto es, a través de una distribución equitativa del poder en los ámbitos de decisión política.

La formulación de la democracia paritaria supuso, a su vez, una reformulación a las primeras Declaraciones de Derechos ${ }^{2}$, para incluir a las mujeres en el contrato social y, por tanto, reformular el pacto político inspirador de las sociedades democráticas (García de Enterría, 1981, p. 46) ${ }^{3}$. Para ello era imprescindible superar la subyugación estructural de las mujeres, adoptar una perspectiva de género, potenciando el desarrollo de una mayor libertad e igualdad femenina con vistas en la consecución de satisfacer la autonomía de las mujeres, directa e indirectamente (Balaguer Callejón, 2005).

La democracia paritaria responde así a un perfeccionamiento idílico de las democracias liberales, cada vez más real, y posibilitada a través de la cláusula del Estado Social y Democrático de Derecho y el principio de igualdad material (arts. 1.1 y 9.2 CE). Así, la democracia paritaria, se plasma en una proyección de la universalidad de la ciudadanía en el poder del Estado (Morales, 2015, p. 306) 4 . Pero, ¿realmente puede hablarse de ciudadanía universal sin extender los postulados de la democracia paritaria al ámbito de las esferas de poder económico y social? La distinción histórica del desempeño de papeles propios de hombres o de mujeres, articulado en torno a los condicionantes sexo y género ${ }^{5}$ (división social del trabajo) supone un reto no superado por los Estados democráticos, ya que las mujeres no han sido un sujeto pleno de derecho en el sistema político, pero, especialmente, aún no se las tiene en cuenta en el terreno social y económico (Esquembre Cerdá, 2018). Es por ello que no puede hablarse de una plena democracia en términos de paridad, en tanto no se supere la exclusión de las mujeres de los ámbitos de toma de decisiones y poder en el espacio privado. Y, este, es un reto que debe afrontarse desde una óptica transversal, extendiendo la igualdad hacia todas las esferas de la sociedad para hacerla realmente efectiva y no parcelada únicamente en torno a lo público.

Debe partirse de las ideas que conforman la Recomendación no 25 de la Convención sobre la eliminación de todas las formas de discriminación contra la mujer (CEDAW), referente a medidas especiales de carácter temporal para acabar con la discriminación que sufren las mujeres. Es decir, la democracia paritaria no puede lograrse de forma plena y transversal sin la adopción de acciones positivas de gran calado. Solo así el Estado Social y Democrático de Derecho podrá superar la cuestión social del siglo XXI: la desigualdad entre mujeres y hombres en el ámbito social y económico (Lousada Arochena, 2004, p. 41).

El mundo económico y, especialmente, las empresas cotizadas como expresión máxima del poder económico, condicionan de forma opaca las decisiones del poder público

\footnotetext{
${ }^{2}$ Dictadas atendiendo a un destinatario concreto: el sujeto masculino, propietario y blanco. Todos sus derechos se proclamaron sobre dicha base y, es por ello, que ello inspiró, hasta nuestros días, la totalidad del ordenamiento jurídico.

${ }^{3}$ Se trae a colación el significado de la Constitución como decisión del pueblo, por ende, un contrato social. Este pacto social establece derechos y libertades fundamentales que constituyen un sistema preceptivo que emana directamente de la soberanía popular.

${ }^{4}$ La participación política real requiere un estándar no excluyente para poder hablar de una "ciudadanía democrática efectiva".

${ }^{5}$ Como móviles de discriminación previstos en el art. 14 CE, dónde el género, un condicionante más cultural que biológico, entraría dentro de la cláusula de cierre: cualquier otra circunstancia personal o social.
} 
que perciben como contrarias a sus intereses o a los de los mercados. La infrarrepresentación femenina en dichas cotas de poder, indirectamente, condicionaría así el papel que debiera tomar el Estado en la implantación real de la igualdad entre mujeres y hombres en este ámbito concreto. Un reflejo de todo ello es la frustración de las propuestas en torno a lograr una composición equilibrada en los consejos de administración de las sociedades cotizadas. En nuestro país, finalmente, se optó por adoptar disposiciones no vinculantes (soft law) que no han traído consigo un cambio de la realidad en la cúspide de las sociedades cotizadas (Senent Vidal, 2018).

Parece que aquellas normas tenían más el fin de apoyar la responsabilidad social corporativa que paliar, realmente, la infrarrepresentación de la mujer en esos ámbitos del poder privado. Por ello, hay que llegar a la construcción de una nueva tesis de democracia paritaria en el ámbito social y económico, más allá de lo eminentemente político (Hesse, 1995) ${ }^{6}$. Solo así se logrará una eficacia material de las previsiones de la Constitución y, en concreto, de la igualdad entre mujeres y hombres como elemento del principio democrático que inspira el Estado Social de Derecho. En concreto, debe abrirse paso a la posibilidad de que las mujeres vayan ganando relevancia en los lugares de decisión privada.

El fomento de la diversidad de género en los consejos de administración repercute tanto de forma externa como interna a las sociedades cotizadas, en tanto que puede, no solo contribuir a conformar una imagen responsable de las corporaciones ante la sociedad, sino también combatir la estructura patriarcal de las empresas y del sistema bancario privado. Dada la resistencia del poder privado ante la incorporación de mujeres en sus esferas, ¿por qué no ir pensando en las cuotas como vía para combatir una desigualdad estructural? Solo con la mejora en la tutela de acceso y mantenimiento de la mujer en el empleo y avanzando hacia una corresponsabilidad en torno a los cuidados, ¿puede lograrse una plena igualdad de género en la sociedad? Inexorablemente, además, han de combatirse los estereotipos de género y la socialización histórica y desigualitaria en las empresas desde arriba. Desde luego, sin negar la necesidad de respuestas legislativas en relación a las vicisitudes que plantean la maternidad, la dependencia u otras necesidades de conciliar la vida familiar y personal con la profesional.

Por ello, se propone una tesis de democracia paritaria para el Derecho Privado partiendo de la inspiración de la Teoría del Estado y, en concreto, del poder público (Bingham, $2018)^{7}$, para la búsqueda de similitudes conceptuales con el poder privado. Se pretende así dar una fundamentación constitucional a la misma, para posteriormente, desde esa óptica reformular el régimen jurídico vigente en nuestro país en torno a la composición

\footnotetext{
${ }^{6}$ En tanto que la relación del Derecho Constitucional y el Derecho Privado debe entenderse como una primacía del primero (art. 9.1 CE) y, así, puede afirmarse que la Constitución supone una guía para las directrices e impulsos que haya de tomar el segundo. Sobre todo, en lo que concierte al derecho fundamental a la igualdad entre mujeres y hombres, ya que es una expresión concreta de un orden objetivo de valores que debe estar presente no solo en la vida estatal sino en toda la vida jurídica.

${ }^{7}$ Al igual que los ministros y demás funcionarios deben ejercer de buena fe las facultades conferidas por la ley, en tanto decisión expresada por voluntad general de los ciudadanos, los miembros del consejo de administración también, en tanto que los poderes a ellos conferidos son determinados por la voluntad social. En ningún caso, los miembros del consejo de administración pueden extralimitarse de las facultades conferidas en los estatutos, cfr. arts 23 y 245.1 LSC, representando los estatutos el papel de la ley como decisión de la voluntad social.
} 
equilibrada de los consejos de administración de las sociedades cotizadas, que debe optar por incorporar un carácter obligacional cuyo incumplimiento conlleve sanciones, dejando de lado las meras recomendaciones.

\section{La justificación constitucional de extender la Democracia paritaria al Derecho Privado}

La proclamación de la igualdad como valor superior del ordenamiento jurídico no solo supone que esta, junto a la libertad, la justicia y el pluralismo político, forme parte de una mera declaración de intenciones del Constituyente, sino que, la igualdad, elevada así a la máxima categoría de norma con rango constitucional incardina y orienta el ordenamiento jurídico por completo (Peces Barba, 1984). Los valores constitucionales juegan un papel que subyace a la producción del Derecho por parte del legislador ordinario, ya que el sistema axiológico-constitucional no solo recorre la Constitución y sirve de interpretación a la misma, sino que marca la meta del derecho positivo: el cumplimiento de los valores superiores a través de la realización efectiva del Estado Social y Democrático de Derecho; a través de los derechos fundamentales. Suponen, así, un parámetro interpretativo del sistema normativo al completo (Robles Morchón, 1992, p. 33) ${ }^{8}$.

El Constituyente fue consciente de la relevancia de la igualdad en tanto objetivo a conseguir pro futuro, ya que, al proclamarlo, es consciente de la inexistencia de una igualdad plena y efectiva en la sociedad (de ahí, el mandato promocional del art. 9.2 CE); de tal forma que marca, recíprocamente, el final de un camino (Rodrigues Canotilho, 2017, p. 46): la remoción de las desigualdades sociales y, por tanto, la realización idílica de la cláusula del Estado Social (art. $1.1 \mathrm{CE})^{9}$. En este marco, la plena consecución de la libertad y de la igualdad suponen una exigencia de justicia social y, por ende, no pueden entenderse una sin la otra; tampoco puede comprenderse el reconocimiento de la igualdad (formal) como derecho (art. $14 \mathrm{CE}$ ), sin el poder equilibrador de los poderes públicos (art. 9.2 CE).

El que nos proponemos enfrentar ahora no es un problema ajeno al nacimiento del Estado Liberal, donde el recocimiento de la libertad y de la igualdad (formal) llevarán necesario reconocimiento de la propiedad privada como derecho fundamental y cuestión esencial en el desarrollo de los derechos y libertades pretendidas por la burguesía, aunque con un eminente carácter individualista. Sin embargo, el Estado Social proclama la libertad y la igualdad (formal y material) con una proyección social (Parejo Alfonso, 1990, p. 125), que guarda una proximidad conceptual al conectarse con el nacimiento mismo de las sociedades mercantiles o de capital y, posteriormente, las cotizadas como tipología

\footnotetext{
${ }^{8}$ Carecería de sentido interpretar o fundamentar los derechos humanos, en concreto, la igualdad entre mujeres y hombres, sin partir de la base de unos deberes morales articulados en torno a los valores superiores del ordenamiento. Esto es, en conexión con estos últimos para dar una coherencia al sistema axiológico-constitucional buscando una coherencia interpretativa.

9 "La igualdad es un valor protegido por sí mismo", una finalidad a concretar y hacer realidad por parte de los poderes públicos, pero no es el punto de partida: "la igualdad es un fin, no un medio, y alcanzarla es una de las tareas fundamentales del Estado".
} 
concreta de aquellas en tanto perspectiva social de la libertad de comercio. Es inherente a estas entidades su vinculación con la libertad de empresa (art. $38 \mathrm{CE}$ ), pero no olvidando su conexión preferente con el derecho fundamental de asociación (art. 22 CE).

Es en la etapa en que aparecen las sociedades mercantiles o de capital (o sus primeros gérmenes) cuando se produce una reformulación de las pretensiones burguesas que inspiran el Estado Liberal, sin llegar a la etapa del Estado Social, para inspirar una visión colectivizada de la libertad de comercio, desde una óptica empresarial. Así, ejercitando conjuntamente ambos derechos, se emprendió el camino hacia una nueva democracia liberal en que la asociación de muchas libertades de comercio se aunará en una gran libertad de empresa, conjunta, ejercida por un ente conformado por la coexistencia de propietarios más pequeños concurrentes en torno al mismo. Esto es, una ficción jurídica que tendrá personalidad propia y podrá competir con otros propietarios individuales, pero más fuertes que aquellos que se han reunido para acabar con las oligarquías monopolísticas de la época e instaurar así un mercado en el que haya más posibilidades de competencia y, por tanto, que sea más democrático. Es así que el nacimiento mismo de las sociedades mercantiles tiene una inspiración eminentemente democrática y presidida por el principio de igualdad que inspira el Estado Liberal de Derecho.

Ese carácter democrático, sin embargo, predomina con carácter externo a las nuevas instituciones que han surgido. No importaba sino la democracia ad extra, en el mercado y en aras de mejorar las condiciones de competencia, rompiendo de barreras de entrada al mismo: más libertad que igualdad; no obstante, permitiendo un ejercicio de la libertad de empresa en igualdad de condiciones en sede del mercado, evidencia de que la libertad no puede entenderse sin la igualdad (Aragón Reyes, 1995, p. 20) ${ }^{10}$. Sin embargo, el principio democrático que inspira el Estado Social y Democrático de Derecho exige también una nueva visión jurídico-constitucional sobre las sociedades mercantiles: la búsqueda de los valores democráticos no solo en el mercado sino también en la esfera interna de las mismas. Esa visión ad intra tiene que ver con el carácter democrático que debe inspirar cualquier estructura corporativizada, pues la fundamentación constitucional e inspiración dogmática de las sociedades mercantiles descansa sobre el reconocimiento constitucional de la libertad de asociación como derecho fundamental más próximo al hito histórico que significaron estas, más allá de la propia libertad de empresa, ya que esta será ejercida por parte de estructuras corporativas, dejando atrás las individuales libertades de comercio (Galgano, 1981) ${ }^{11}$.

La estructura social de la empresa, articulada a través del Derecho de Sociedades hace que lo individual (libertad de empresa) devenga en una estructura social compleja (derecho de asociación) que subyace a su funcionamiento y al ejercicio mismo de la propia libertad de empresa (Pérez Escalona, 2007, p. 406). Desde un punto de vista no estático sino dinámico lo relevante para el ejercicio de la libertad de empresa a través de una socie-

\footnotetext{
${ }^{10}$ Partiendo de la base de que el contenido esencial de un derecho no puede identificarse con un derecho o libertad ilimitada, el contenido esencial de la libertad de empresa debe situarse no en la libertad sino en la igualdad, al menos en el ejercicio de esa libertad. Igualdad sería el aspecto objetivo (libertad de competencia en los mercados en igualdad de condiciones, por ejemplo) y la libertad el aspecto subjetivo (libertad de acceso, mantenimiento y cesación).

11 "El gran capital, que hasta entonces era comercial, se transforma en capital industrial".
} 
dad mercantil es la conjunción de personas que se asocian con el interés de llevar a cabo un fin común, más allá de la propiedad de los medios productivos o la limitación de los riesgos que se asumen en el mercado (Rey Martínez, 1994, p. 328) ${ }^{12}$. Es decir, lo relevante, a mi juicio, no viene dado por el fin lucrativo en tanto objetivo común de los socios sino la comparecencia de dos o más personas que concurren en el contrato de sociedad, que no es un mero negocio jurídico bilateral. Así, surge una persona moral encaminada al cumplimiento de unos fines, normalmente lucrativos, pero lo relevante no es la empresa como tarea a ejecutar sino como organización constituida en torno a una unidad jurídica corporativizada: la sociedad; lo que plantea un cambio en la titularidad y el ejercicio de la libertad de empresa no unilateralmente, sino en virtud de los acuerdos sociales (Tomillo Urbina, 2013) ${ }^{13}$.

Además, la organización jurídico-corporativa de la sociedad se asemeja conceptualmente a la organización jurídico-política e institucional de un Estado de Derecho. Aunque no de forma idéntica, conceptos propios de la Teoría del Estado como lo es el pacto social que inspira toda Norma Fundamental (Sørensen, 2010) ${ }^{14}$, la soberanía o la separación de poderes pueden extenderse de forma teórica y con carácter epistemológico al funcionamiento y relación de los órganos societarios y a la sociedad propiamente dicha, haciendo un cierto paralelismo comparativo con el Derecho de Sociedades.

1) El contrato de sociedad es la base de la sociedad mercantil, supone la concurrencia de personas físicas o jurídicas que, a través de dicho vínculo negocial, deciden colaborar con carácter permanente y estable en el tiempo para la realización de un fin que entienden como propio, colectivo y, por tanto, común. Ese fin, que desde el origen más remoto de los tiempos es el ánimo de lucro, si bien elemental, es secundario en relación a la agrupación voluntaria de personas en torno a un interés común a realizar, independientemente de la naturaleza de ese propósito colectivo articulado en torno a la sociedad y regido por esta (Ibañez Jiménez, 2013) ${ }^{15}$. No puede considerarse como un contrato strictu sensu, ya que no hablamos de un negocio jurídico bilateral, sino que es un acuerdo colectivo sin existir una confrontación de intereses entre los socios (al menos en el origen); más bien, al contrario, puede hablarse de intereses compartidos. Supone pues,

\footnotetext{
${ }^{12}$ La propiedad privada representa como derecho subjetivo la apropiación de bienes patrimoniales, sin embargo, la libertad de empresa es un "momento dinámico" de aquella, pues supone destinar esos bienes al desarrollo de una actividad de distribución de bienes o la prestación de un servicio. Combinar propiedad y libertad de empresa, a través del Derecho de Sociedades, supone que "se puede ser empresario sin ser propietario".

${ }^{13}$ En suma, la insuficiencia de medios económicos por si solo o la imposibilidad de asumir grandes riesgos para emprender negocios de entidad mayor, obliga al empresario individual a asociarse con otras personas: surgen los "empresarios sociales" o sociedades mercantiles.

${ }^{14}$ Ciertamente, una sociedad de capital se caracteriza por la existencia de relaciones de todos los socios ("comunidad") en torno a un ente en torno al que hacen "grupo", intereses comunes, más allá de meros derechos y obligaciones. Aunque, ciertamente, ese interés común o general sea ganar dinero y no gestionar la empresa, de forma directa. En torno al Estado también se estructura una "comunidad" de ciudadanos y de "sentimiento", entendida como grupo común de intereses, más allá de las relaciones de los ciudadanos con el Estado y entre sí. Esto es, más allá de los derechos y deberes fundamentales hay un sentimiento político común e identitario.

${ }^{15}$ No es la sociedad la interesada en enriquecerse sino los socios. Por eso, "la sociedad expresa tanto en su plano externo como interno, expresa, en fin, el ejercicio de un derecho constitucionalmente reconocido", el de asociación de los socios que la constituirán para llevar a cabo los fines económicos de una actividad común.
} 
desde una visión dogmática, la materialización de un acuerdo o pacto social que deja de tener relevancia una vez la sociedad nace, el contrato de sociedad no sufrirá modificaciones, sino que serán los estatutos sociales, en tanto norma básica de este nuevo ente creado, los que serán revisados para adaptarse a las nuevas exigencias del mercado y de la propia sociedad mercantil, de acuerdo con sus previsiones y las de la ley. Por consiguiente, puede desaparecer el fin último de la sociedad, puede modificarse su objeto social y, por tanto, su industria a llevar a cabo, e incluso desaparecer, pero no el momento determinante en que se produce la concurrencia de una serie de personas naturales coordinadas en torno a la creación de un ente autónomo, con personalidad jurídica propia.

2) Los estatutos sociales supondrían la norma básica y fundamental de la sociedad mercantil constituida, la expresión última del pacto social y, por tanto, el régimen normativo que regirá la vida social, más allá de lo que, de forma imperativa, han predeterminado la Constitución y las leyes; en tanto límites a la autonomía de la voluntad de los socios (por ejemplo, los principios configuradores de un tipo societario u otro). Si bien las leyes disponen con carácter general una serie de elementos que los estatutos sociales deben contemplar, se deja cierto margen de maniobra al acuerdo colectivo de los socios, a la vez que se imponen límites. Por consiguiente, la denominación social, su objeto, domicilio, capital social o la posición jurídica individual de los socios en relación con aquel (principio plutocrático), el régimen de adopción de acuerdos y la composición y funcionamiento de los órganos sociales, son una previsión genérica a contemplar ex lege en los estatutos, además de otras menciones que, por decisión de los socios, se harán constar en la norma estatutaria. En definitiva, lo más significativo es el papel que juegan los estatutos sociales, más allá de sus concretas previsiones: la regulación básica y fundamental de una entidad corporativa (García Cruces, 2016, p. 141$)^{16}$, cuyo devenir queda ligado a sus previsiones en relación a la adopción de los acuerdos sociales (soberanía societaria) o la competencia de los órganos societarios (separación de poderes en el seno de la organización).

Los estatutos, como resultado de un pacto social, expresan así un contenido que permite realizar una analogía explicativa poniendo la sociedad y sus órganos en relación con el sistema organizativo-institucional de una constitución política. $\mathrm{Al}$ igual que un individuo al adquirir la condición de nacionalidad y, por tanto, de ciudadanía, puede ser sujeto de derechos y obligaciones en un Estado, las personas que adquieren participaciones y acciones adquieren la condición de socio y, por tanto, pasan a ser sujetos de derechos y obligaciones en relación con la sociedad constituida. Es decir, la adquisición de la condición de socio supone la participación de un individuo en un pacto social que devendrá en la creación de una organización concreta en la que tendrá derechos y obligaciones para con los socios y la sociedad: una ciudadanía societaria ad intra.

${ }^{16}$ Los estatutos sociales expresan la regulación que los socios acuerdan para la "vida social". 
3) La soberanía de la sociedad y, por tanto, el poder originario de la organización recae en la concurrencia de los socios que, al igual que en la creación del pacto societario (articulado a través del contrato de sociedad), deberán decidir sobre las cuestiones más relevantes para la sociedad, cuando así lo exige la ley y los estatutos sociales. Lo cual debe entenderse sin perjuicio de que la lógica económica nos haga conectar con que no existe una igualdad plena entre los socios, sino que su relevancia en la toma de decisiones viene predeterminada por un principio plutocrático que nos indica que el poder de decisión del socio, individualmente considerado, viene predispuesto por su aportación dineraria o de otro tipo en el capital social. En un sentido restringido, realmente la ciudadanía societaria viene predeterminada por las acciones y participaciones, de tal forma que son las aportaciones individuales las que otorgan un grado de poder en la toma de decisiones societarias u otro, representada por el capital social desembolsado por todos los socios. Y este condicionante, a pesar de dotar de relevancia al interés o ánimo de lucro, lo que hace es correlacionar el juego de la democracia y, por tanto, la libertad en el seno de las compañías en relación con la realidad económico-patrimonial que representa la sociedad y su actuación en los mercados. Sin que pueda negarse su carácter democrático, lo que el principio plutocrático rige es la adopción de acuerdos, predeterminando el valor del voto de cada socio en función de las aportaciones de aquellos en el capital social, de acuerdo con la realidad mercantil que inspira estas estructuras. Cabe, pues, destacar que su inspiración es de corte corporativo y no puede rechazarse un valor eminentemente democrático que fundamentó el surgimiento mismo de estos fenómenos, con la vista puesta en mejorar la libre competencia en el mercado mejorando la igualdad de salida de todos los competidores.

4) El poder soberano de la sociedad recae en la junta general, pues a través de este órgano las sociedades expresan la voluntad social (Sebastián Quetglas, 2013). Esta voluntad social debe entenderse desde la lógica de la ciudadanía societaria expresada anteriormente, por eso es una derivación de la decisión de los socios. Es decir, la voluntad societaria se expresa a través de una vinculación de la sociedad por la conjunción de las voluntades individuales concurrentes de cada uno de los socios (Gil Echeverry, 2012, p. 354) ${ }^{17}$. Además, la conformación de esa voluntad social viene regida por una serie de procedimientos establecidos por los estatutos sociales y las leyes, por ejemplo, a la hora de establecer el régimen de mayorías que debe concurrir para adoptar ciertas decisiones. En suma, los estatutos (o, en su defecto, la ley) vienen a establecer un principio de competencia material entre los órganos societarios, de tal forma que existe una semejanza conceptual (no exhaustiva) con el principio de separación entre los distintos poderes del Estado, reservando a la junta general las decisiones más importantes.

${ }^{17}$ Es el órgano social que en primera y última instancia toma la iniciativa y decide del desarrollo de la vida social y, además, se le faculta para decidir de todo aquello que, por previsión legal o estatutaria, no queda en manos de otros órganos de forma expresa. 
Es el órgano supremo de decisión en una sociedad de capital, como lo fuera el Parlamento emanado de la soberanía popular a través del voto de la ciudadanía. Solo que aquí el valor del voto viene predeterminado por el nivel de aportación al capital social de cada socio y no tanto por su posición individual como persona natural, que conducen a identificar una soberanía societaria no personificada sino de carácter deshumanizada o patrimonializada.

5) El órgano de administración de las sociedades de capital podría identificarse con el órgano ejecutivo de la sociedad ya que sus competencias se reducen a la administración o gestión societaria. En las sociedades más relevantes, las cotizadas, de forma obligatoria, la modalidad de administración que se toma es la de consejo de administración (ex art. 529.1 bis LSC), un auténtico órgano de gobierno nombrado por el soberano órgano societario, la junta general. En estas sociedades el órgano es colegiado y, por tanto, sus decisiones, se someten a un procedimiento de decisión colegial que exige un acuerdo de mayoría. El número mínimo para poder hablar de órgano colegiado es de tres miembros (art. 242.1 LSC) dejando la determinación del número de administradores que integren el consejo de administración a la autonomía de la voluntad societaria, ello si determinando, al menos, el número máximo de sus miembros si no se determinara numéricamente el número concreto de los miembros que lo componen, extremo sobre el que la junta general tomará la decisión final. Su régimen de funcionamiento y organización interna, puede venir determinado en las previsiones estatutarias o no, aunque sería lo ideal. A veces, el propio consejo puede determinar su régimen de funcionamiento interno (art. 245.2 LSC), sin que puedan quebrar previsiones de derecho necesario absoluto sobre reglas de la convocatoria o el quorum mínimo para su constitución. Su papel se asemeja al del poder ejecutivo del Estado, que tiene cierto margen de maniobra, pero debe responder al poder soberano del Parlamento que ejerce un control sobre el mismo, al igual que el consejo de administración responde ante la junta general que le nombra.

Aplicar y extender los conceptos propios de la Teoría del Estado al Derecho de Sociedades no es tan descabellado, más aún cuando el papel real de las sociedades cotizadas en nuestros días es el de condicionar la gobernanza pública y las instituciones que integran una democracia avanzada por la relevancia de los mercados en la conformación del ordenamiento jurídico (García Mexía, 2008, p. 101), que ha venido adoptando una tendencia neoliberal en las últimas décadas en detrimento de los derechos sociales de la ciudadanía. La evidencia del condicionamiento de las decisiones del poder político se hizo latente en virtud del papel que tomaron las grandes empresas cotizadas en la redacción final del art. 75 LOIEMH, sobre la composición equilibrada de los consejos de administración en relación al principio de igualdad efectiva entre mujeres y hombres, aunque no fuera manifestada públicamente y de manera expresa.

A pesar de que las sociedades se rigen por el Derecho de Sociedades (art. 1.3 L.0. $1 / 2002$, de 22 de marzo, reguladora del derecho de asociación), no puede obviarse el 
origen de las sociedades mercantiles en tanto asociación de pequeños propietarios que buscan competir con otros más importantes en un mercado oligopolístico. Y es que, este acontecimiento, es primordial para entender la visión democrática que el fenómeno societario introduce en el mercado que, por supuesto, no puede ser obviada: el carácter asociativo de las sociedades de capital. Los principios que inspiran el derecho de asociación son igualmente atribuibles a las sociedades: asociarse sin autorización previa para competir en el mercado en tanto fin lícito amparado por la Constitución (sin perjuicio de la obligación registral), que proclama la libertad de empresa en el marco de una economía de mercado (art. 2.1 y 2 L.0. 1/2002 en relación con el art. 38 CE); la semejanza entre el acuerdo de constitución y el contrato de sociedad en tanto acto fundacional o escritura de constitución y entre los estatutos de la asociación y la sociedad (arts. 5, 6 y 7 L.0. 1/2002 en relación con el art. 1665 CC); y, fundamentalmente, su sometimiento a la Constitución y al resto del ordenamiento jurídico, en particular, las previsiones legales de carácter imperativo contenidas en la Ley de Sociedades, no modificables por la autonomía de los socios (arts. 9.1 CE y 2.4 L.0. 1/2002). También, una primera lectura del Capítulo III de la L.O. 1/2002 hace posible asemejar las instituciones societarias a las de la asociación y, aunque sea menos relevante en el terreno asociativo, tanto en ámbito societario como en el derecho de asociación, la inscripción registral (art. 10 L.0. 1/2002 en relación con el art. 119 CCom) cumple un papel a los efectos de publicidad en aras de la salvaguarda de la seguridad jurídica en el tráfico, aunque es cierto que en el caso de las sociedades de capital la publicidad registral cumple un papel constitutivo que no es propio del régimen jurídico de la asociación (art. 20 LSC en contraposición con lo dispuesto en el art. 5.2 L.0. 1/2002).

Sin perjuicio de las peculiaridades de uno y otro régimen, hay una vinculación por entero de la Constitución respecto de la asociación y de las sociedades de capital, de tal forma que los valores democráticos de libertad e igualdad, así como el pluralismo debieran jugar la suerte de inspirar la ordenación jurídica de las sociedades de capital de una forma parecida a la de asociación. Sin embargo, no debe obviarse la especificidad propia del Derecho de Sociedades en tanto soberanía societaria deshumanizada, articulada a través de títulos, esto es, la actuación mediata de los socios a través de las acciones; en contraposición con la soberanía asociativa, compuesta de personas naturales que actúan en el marco asociativo de forma directa e inmediata. Así, no puede obviarse ni desplazarse el régimen de conformación de la voluntad societaria, además, tampoco sería efectivo ni siquiera operativo en aras de la consecución de una composición equilibrada del órgano de administración de la sociedad.

Por consiguiente, no afectaría a la esencia de la sociedad ni al principio plutocrático que inspira toda sociedad de capital la imposición de obligaciones por parte del poder público como medio para lograr una diversidad de género plena en sede del consejo de administración. Ello no afectaría, en esencia, a la soberanía societaria, aunque mermaría la autonomía de la voluntad societaria que quedaría predeterminada por la decisión pública de someter a un régimen de democracia paritaria el órgano ejecutivo de las sociedades. Así, habría de someterse a un filtro de ponderación, ya que van a confrontar, de un lado, el 
derecho a la igualdad y no discriminación entre mujeres y hombres y, de otro, la libertad de empresa. Pero no solo, porque, en este caso, hay que incorporar el parámetro asociativo como canon de interpretación de las sociedades en aras de lograr una democracia en términos de paridad, ¿sería suficiente con un mero juicio de ponderación entre derechos fundamentales que confrontan?

Se enfrentan derechos cuya proclamación ya responde a una separación dicotómica entre derechos civiles y políticos o de primera generación (categoría en que residiría la igualdad, pero también la libertad de asociación, en tanto derechos fundamentales) y derechos económicos, sociales y culturales o de segunda generación (la libertad de empresa como derivación dinámica del derecho de propiedad privada, de primera generación). Sin embargo, la propia conexión entre derecho de asociación y libertad de empresa son un argumento a favor de la desconsideración de categorías enfrentadas a la hora de hablar de distintos tipos de derechos fundamentales; además, como ejemplo, la propiedad no es un derecho materialmente efectivo si uno no encuentra ocasión de serlo (Alexy, 2007, p. 176), y por tanto no puede hablarse de un reconocimiento inmediato. Por tanto, no puede hablarse de que la propiedad sea un derecho definitivo, ni siquiera formalmente; por el contrario, la igualdad es un derecho moral que, desde la faceta del reconocimiento formal, es inmediato, formulado con vocación general erga omnes, aunque requiere de la intervención del Estado para su realización efectiva (art. 9.2 CE). Entonces, no puede hablarse de una primacía por razón de la sistemática de la estructura jurídico-constitucional y, precisamente, en relación a la parte dogmática de la misma.

Hay que partir de la interpretación y significado previos de los valores constitucionales, de la axiología constitucional, pues la ponderación solo es parámetro de interpretación para un concreto conflicto entre derechos fundamentales, no en abstracto. Aquí el interés general de las sociedades democráticas es un fundamento último, pues ha de entenderse que la máxima consecución posible de tales valores es la consecución del interés general del Estado Social y Democrático de Derecho ${ }^{18}$. La igualdad y la libertad no pueden entenderse una sin la otra. Solo de estas premisas puede partir el eventual juicio de ponderación que concretamente protagonizará el valor, principio y derecho de igualdad entre mujeres y hombres en contraposición con la libertad de empresa, y la vinculación de esta última, en ámbito de las sociedades de capital, con el derecho de asociación, que introduce un carácter democrático a la realidad empresarial de nuestros días, en un plano interno y no sólo externo.

Pasando al papel concreto del juicio de ponderación y conectando con lo que acaba de ser expuesto hay que tener presente que la igualdad al proclamarse como derecho fundamental positiva un valor y principio constitucional y, por tanto, expresa un deber ser al derecho ordinario que se construya por parte del legislador (Prieto Sanchís, 2013, p. 67) ${ }^{19}$.

\footnotetext{
${ }^{18}$ Precisamente, ahora no importa garantizar la libertad de empresa en el mercado (esfera externa) sino asegurar un mínimo inquebrantable por el Derecho Privado que está identificado con los valores constitucionales ante una expansión desmedida de la libertad de empresa y la preeminencia del mercado sobre la autonomía de la política.

19 "El constitucionalismo de los derechos se caracteriza precisamente por la rigurosa distinción entre vigencia o mera positividad y validez, siendo esta última dependiente de un juicio sobre la adecuación de las leyes al programa constitucional".
} 
La regla de la proporcionalidad es el método a través del cual, tradicionalmente, se han interpretado los conflictos entre derechos fundamentales; a través de las pautas de necesidad, adecuación y proporcionalidad, como último filtro. Si bien la libertad de empresa sería menoscabada, en tanto que la soberanía societaria quedaría restringida, al imponer el Estado una obligación de estructurar el consejo de administración en términos de paridad y vinculando, por tanto, el ejercicio de la autonomía societaria que corresponde al órgano supremo de la sociedad de capital, la junta general; tales obligaciones serían una expresión concreta de acción positiva en ejercicio del mandato constitucional del art. 9.2 CE. La necesidad de adoptar disposiciones vinculantes en torno a la igualdad de género en el consejo de administración de las sociedades cotizadas, en concreto, suponen en abstracto la realización de la igualdad efectiva propia de un Estado Social y Democrático de Derecho, una asignatura pendiente de la que, como se señaló, era consciente el legislador constituyente al precisar la igualdad no solo como derecho sino como un valor superior del ordenamiento jurídico y un principio de interpretación privilegiado junto a la libertad, como elementos centrales de la democracia y vinculados insoslayablemente a la dignidad humana y al libre desarrollo de la personalidad (art. 10.1 CE).

En suma, la libertad de empresa sufrirá un menoscabo en la elección de los miembros de los órganos de administración y gestión de la empresa, sin embargo, esa limitación está justificada para la realización de un objetivo de la democracia en sí misma: la igualdad. Así, puede humanizarse la sociedad mercantil sin atentar al régimen plutocrático que rige la conformación de las mayorías y, por ende, supondría la vigencia y efectividad de la libertad empresarial en términos plenamente democráticos: en situación de paridad. La intromisión en la misma en pro de la igualdad entre mujeres y hombres no es arbitrario ni proporcionado, respeta el contenido esencial de la libertad de empresa (acceso, mantenimiento y salida del mercado); no es arbitrario, ya que va ligado a la realización de un interés general de la democracia. A lo sumo, el sacrificio de la libertad de empresa se reduce a la elección de los miembros del consejo de administración por una razón de interés general: la igualdad efectiva entre mujeres y hombres; teniendo presente el art. 128.1 CE que somete las distintas formas de riqueza al interés general, independientemente de su titularidad y, para ello, el Estado se marca como objetivo regular una forma más democrática de participación en las empresas (art. 129.2 CE en relación con los arts. 14 y 9.2 CE), logrando la participación de las mujeres en tanto mayoría poblacional. Esto es, priorizar el nombramiento de mujeres que estén en condiciones de responder a las exigencias de mérito y capacidad determinadas por la voluntad social del accionariado societario, como sacrificio razonable y justificado -no arbitrario- de la propia libertad empresarial. Sin olvidar la libertad de asociación en tanto derecho fundamental de primera generación (parámetro de optimización) que respaldaría la intervención estatal del lado de la igualdad más allá de la libertad de empresa, dotando a esta última de un carácter plenamente democrático desde una perspectiva de género, sin dejar de lado la exigencia de democracia en la estructura corporativa que subyace a las sociedades de capital, pero quedando a salvo, ello si, el principio plutocrático. 


\section{El significado de las sociedades cotizadas en las democracias contemporáneas}

Las relaciones entre el sistema democrático instaurado por el Estado Social y Democrático de Derecho y el mercado, pone en muchas ocasiones en entredicho la superación del Estado Liberal por la forma de Estado vigente. Esto ha supuesto, un sometimiento cada vez más exacerbado del capitalismo sobre el poder del Estado, inspirado por una corriente de corte neoliberal. La economía de mercado es el marco en que se desenvuelve el sistema de relaciones de producción en las sociedades contemporáneas (art. 38 CE), sin embargo, hay que buscar un equilibrio entre las necesidades y aspiraciones de los agentes intervinientes y participantes del mercado y los objetivos o fines a cumplir por el poder supremo del Estado (art. 1.1 CE).

Precisamente, el surgimiento del Estado Social de Derecho viene predeterminado por la necesidad de superar los abusos de unas clases sociales sobre otras ante la no intervención del Estado Liberal, que perdería así de forma progresiva su carácter democrático, si es que alguna vez lo fue. No puede afirmarse la plenitud democrática de una sociedad articulada en torno a un Estado si ese Estado no puede cumplir sus objetivos, además dando respuesta a las exigencias sociales. Al igual que ocurriría con la cuestión social protagonizada por el conflicto capital-trabajo que hicieron reformular el Estado Liberal, con una primera intervención en los asuntos sociales y económicos, el Estado Social y Democrático de Derecho debe dar respuesta a una nueva cuestión social, sin que pueda admitirse una indiferencia del poder estatal ante la subyugación de la mujer en el ámbito de las sociedades cotizadas. Y es que estas sociedades determinan, al menos de forma indirecta, el rumbo que va tomando el Estado y las políticas que este adopta, sobre todo en tiempos en que la necesidad se agudiza por ciertas crisis, como la reciente crisis económica de la que aún persisten secuelas (Cidoncha Martín, 2006, p. 57) ${ }^{20}$.

Las sociedades cotizadas y su papel en los mercados bursátiles condicionan las decisiones públicas, puesto que como se ha podido percibir ha habido una prevalencia de lo económico a lo social, traspasando en muchas ocasiones la búsqueda de un equilibrio, orientando la balanza en favor de las corrientes más neoliberales. Esto supondrá, entre otras cosas, el mantenimiento de recortes en derechos sociales o derechos fundamentales de segunda y tercera generación que han trasvasado la necesidad de su adopción más allá de un momento coyuntural, aceptando así la visión de las corrientes más neoliberales que han hecho persistir las reformas adoptadas. La productividad y competitividad empresarial ha venido siendo atendido como un valor absoluto, en detrimento del contenido constitucional. Además, la sociedad anónima (todas las cotizadas adoptan este tipo societario, vid. arts. 495 y ss. LSC) tiene una vocación abierta a la generalidad del público inversor y acceso a los mercados (De Carlos Beltrán, 2013) ${ }^{21}$.

\footnotetext{
${ }^{20}$ Se plantea un problema nuevo: cómo asegurar un mínimo insoslayable del Estado Social y Democrático de Derecho frente a una expansión desenfrenada del mercado y de sus intereses.

${ }^{21}$ Esto es, la sociedad anónima se concibe como una sociedad con vocación de acceso al mercado y, por tanto, responde al modelo anglosajón de public company, no por ser pública sino por su eventual conexión con todo inversor que lo desee. Son reflejo de ello la libre transmisibilidad de acciones o que el capital social se encuentre distribuido entre accionistas que no participan de la administración societaria.
} 
Enlazando con el asunto que nos proponemos afrontar, la igualdad efectiva entre mujeres y hombres, la experiencia ha puesto, también, sobre la mesa la vigencia de esa gobernanza neoliberal que, cada vez y con mayor intensidad, se coloca frente al Estado como imposibilidad fáctica de cambiar la realidad (Zinti, 1993) ${ }^{22}$. Es decir, un detrimento del poder público emanado de la soberanía popular que conforma el Estado Social y Democrático de Derecho, sobre todo, condicionando las decisiones del poder político. Expresión significativa de este fenómeno es la resistencia de las grandes empresas cotizadas en torno a la adopción de la Ley Orgánica 3/2007, de 22 de marzo, para la igualdad efectiva de mujeres y hombres; y, expresamente, en la formulación que había de adoptar el art. 75 de la misma.

La consecución de la igualdad de género en los consejos de administración no solo es relevante de cara a lograr una sociedad más democrática y participativa que tenga en consideración a las mujeres como parte significativa de aquella. Muchos han sido los estudios que han expresado que la incorporación de mujeres a las empresas y, por tanto, la conformación de corporaciones realmente igualitarias y diversas en términos de género repercutiría positivamente en la productividad empresarial ${ }^{23}$. De tal forma que la existencia de una realidad equitativa para mujeres y hombres en el plano interna de las empresas, su consecución, contribuirá a mejorar tanto las sociedades cotizadas como la democracia en sí misma.

A través de la fórmula gobierno corporativo se han ido apuntando una serie de pautas de actuación en relación a las estructuras y procedimientos societarios. Es relevante el Código Unificado de Buen Gobierno de la CNMV que ya ha atendido a la diversidad de género, como elemento a incorporar para generar valor en la compañía. La introducción de una visión femenina en la gobernanza empresarial supondría la posibilidad de crear unas empresas más equitativas, lo que puede traducirse en la implantación de nuevos procesos de selección y políticas organizacionales comprometidas con las necesidades de las mujeres y orientadas a romper el techo de cristal desde dentro (Salazar Benítez, 2014 , p. 89) ${ }^{24}$. Por otro lado, la generación de valor externo, tanto desde el punto de vista de la ética empresarial y su proyección sobre los skateholders, como de cara al mercado: tomar en consideración las necesidades y demandas de producción de la población femenina (Huerta Viesca, 2009, p. 87). En suma, la ruptura de estereotipos y prejuicios de género que expresan una supuesta y natural incapacidad femenina para la asunción de responsabilidades puede venir de la mano de una composición equilibrada en el consejo de administración. En este sentido, la productividad empresarial puede ser un argumento a favor, ya que, si las mujeres se forman más que los hombres en itinerarios formativos de carácter superior en el ámbito económico y de la administración y dirección de empresas,

\footnotetext{
${ }^{22} \mathrm{Y}$, ahora, el problema está en la interdependencia que las libertades privadas confluyentes en el ámbito de los mercados y la libertad política mantienen, al instaurarse un poder colectivo representado por los mercados de capitales.

${ }^{23}$ Lo que posibilita relacionar el ejercicio del art. $38 \mathrm{CE}$ con el propio art. 14 CE. La libertad de empresa ejercida, materialmente, de forma igualitaria.

${ }^{24}$ Muy necesario, ya que "se ha consolidado un espacio público amparado en las virtudes asociadas a la masculinidad -la competitividad, el éxito en el ámbito profesional, la obsesión por el desempeño (...)- que son las dominantes (...) en la economía y, en general, en la concepción de la raza humana".
} 
la sociedad y las empresas cotizadas están desaprovechando el talento y competencias mayoritarios de que dispone la totalidad de población en este ámbito concreto.

Por otra parte, si bien, las sociedades cotizadas van a seguir teniendo un papel relevante en la conformación de la voluntad publica, condicionando sus decisiones, la incorporación de las mujeres en el ámbito de la gobernanza empresarial, puede suponer también que ese condicionamiento creciente no desemboque en un sometimiento patriarcal inaceptable. Esto es, si las corporaciones que van a decidir del porvenir del Estado, de sus políticas, por la proyección de sus intereses sobre de las decisiones públicas, puede que esta tenga un tinte más igualitario (Figueruelo Burrieza, 2014) ${ }^{25}$.

\section{Una revisión con perspectiva de género del régimen jurídico vigente sobre el nombramiento de los Consejos de Administración}

La experiencia hasta la fecha, ha sido la de adoptar disposiciones no vinculantes, esto es, la técnica legislativa se ha articulado a modo de recomendaciones. En nuestro país, tras la frustración de la Propuesta de Directiva del Parlamento Europeo y del Consejo destinada a mejorar el equilibrio de género entre los administradores no ejecutivos de las empresas cotizadas $^{26}$, en 2012, la referencia sigue siendo el art. 75 LOIEMH. En relación a este artículo, el Anteproyecto de la LOIEMH preveía que la composición equilibrada se debía producir, en un plazo de cuatro años, debiendo incorporar progresivamente (anualmente), el diez por ciento de mujeres hasta alcanzar dicho equilibrio de género. Sin embargo, dicha redacción se quedó en el cajón como lo hizo la propuesta de Directiva de la UE 2012/0299 de 14 de noviembre de 2012, que obligaría a implantar una composición equilibrada en todo el ámbito de la Unión.

Finalmente, la respuesta legislativa fue la propia de un soft law voluntarista de la que hay que identificar los ámbitos subjetivo y objetivo. De este modo, son las sociedades obligadas a presentar cuenta de pérdidas y ganancias no abreviada las que "procurarán" incluir en el consejo de administración un número de mujeres que permita alcanzar una presencia equilibrada (una proporción 40/60 vid. D.A. 1ㅡㅡ LOIEMH) en un plazo de 8 años. Empresas cotizadas en cualquier mercado bursátil de la UE (art. 536 LSC). La referencia "cuenta de pérdidas y ganancias no abreviada" se refiere, por exclusión, a sociedades no cotizadas que, durante dos ejercicios consecutivos, al menos, sobrepasen los siguientes límites: un activo superior a cuatro millones de euros, un resultado del ejercicio neto anual superior a ocho millones de euros, o que sobrepasen una plantilla media de cincuenta empleados (cfr. art. 257.1 LSC). En definitiva, grandes y significativas sociedades que tienen cierta proyección en los mercados (no sólo bursátiles) y, por tanto, en la sociedad. Sin

\footnotetext{
25 "El valor superior de la igualdad consiste en ser iguales en las diferencias", entonces, solo habrá un respeto a dichas diferencias (art. $14 \mathrm{CE}$ ) si se posibilita que las mujeres accedan a la cima de las empresas, reconociendo y protegiendo precisamente las diferencias, muchas veces, construidas socialmente, por las cuales son excluidas.

${ }^{26}$ La Directiva Reading se articuló con vocación de conseguir la composición equilibrada de los consejos de administración de las grandes compañías. Se refería a los consejeros no ejecutivos, con lo cual se tenía la intención de no interferir en la gestión diaria de las empresas. Pese a ello, no se permitió la aprobación de la Directiva.
} 
embargo, no hay carácter vinculante alguno en estas disposiciones y, tras 8 años, tampoco se ha logrado alcanzar una presencia equilibrada, pues la composición femenina de los consejos de administración la grande compañía ronda, en el IBEX 35, el 24 por ciento ${ }^{27}$.

En el ámbito de las sociedades cotizadas, el consejo de administración deberá velar porque el nombramiento de sus miembros favorezca la diversidad de género, indicando para ello que los procesos de selección "no adolezcan de sesgos implícitos que puedan implicar discriminación alguna y, en particular, que faciliten la selección de consejeras en un número que permita alcanzar una presencia equilibrada de mujeres y hombres" (art. 529 bis LSC). Sin embargo, no puede hablarse de una previsión reglamentaria al efecto, ni siquiera un organismo administrativo de control habilitado para auditar posibles incumplimientos de dicho precepto para averiguar si existen sesgos de género implícitos en los procesos de selección o diferencias retributivas entre consejeros mujeres y hombres, de lo que podría hacer las veces la Comisión Nacional de los Mercados y la Competencia (CNMC). Esta formulación que, de entrada, es errónea debido a que el consejo de administración no es el órgano indicado para imponerle velar por la diversidad de genero del consejo de administración, sino que habría de ser la junta general de socios en tanto órgano soberano que nombra a la administración empresarial (art. 214 LSC); sin embargo, muestra la voluntad del legislador en tanto que se muestra comprometido con "facilitar la selección de consejeras", por tanto, existe una búsqueda de lograr una composición equilibrada del consejo de administración, partiendo pues de la realidad: la constatable infrarrepresentación femenina en el poder y toma de decisiones del ámbito empresarial. En definitiva, lo deja a la libre decisión de las sociedades, cuya práctica demuestra que tras más de una década de vigencia del art. 75 LOIEMH, no ha traído consigo un cambio real (Chamorro Domínguez, 2019) ${ }^{28}$.

Sin embargo, frente a este tipo de regulación, contrasta la formulación de la disposición en relación empresas con participación pública (art. 54 LOIEMH): la Administración General del Estado y los organismos públicos y dependientes de aquella "observarán" el cumplimiento de la presencia equilibrada en los consejos de administración en empresas que tengan participación pública en su capital social. La importancia del lenguaje aquí ha de traerse a colación, pues mientras las empresas públicas tienen que procurar una composición equilibrada ("hacer diligencias o esfuerzos para que suceda lo que se expresa"), las empresas -ni siquiera públicas, sino privadas participadas de capital público- deberán lograr una presencia equilibrada en términos de género en tanto que "observarán" el principio de la D.A. 1a LOIEMH y, por tanto, han de "guardar y cumplir exactamente lo que se manda y ordena" ${ }^{29}$. No obstante, un estudio de la Fundación Civio demostraría en 2018 como, cuantitativamente, aún no se había superado la representación mínima del 40 por

\footnotetext{
${ }^{27}$ Según datos del Instituto Europeo para la Igualdad de Género (EIGE), extraídos de la web del Instituto Nacional de Estadística y correspondientes al año 2018.

${ }^{28}$ Sólo con previsiones legales articuladas a modo recomendaciones, tal y como la práctica ha demostrado, no puede lograrse un progreso avanzado pleno y convergente entre los distintos países de la UE. Sólo en aquellos Estados con previsiones vinculantes y sancionables se ha experimentado un cambio en la composición de los consejos.

${ }^{29}$ Diccionario de la Real Academia Española.
} 
ciento de mujeres en los consejos de administración de la mayoría de empresas públicas ${ }^{30}$. Aunque, recordemos, por la naturaleza de las sociedades de capital que, el Estado, en tanto socio, no tendrá más poder que el derecho de voto conforme a su participación en el capital social; entonces, puede no ser el protagonista único y último de la conformación de la voluntad social.

Podría decirse que no se ha producido un logro significativo para implantar una igualdad real en las compañías, empezando desde la cúspide de administración y gestión de las sociedades mercantiles, ya no solo en las que se nutren de inversión privada sino también las que se componen de financiación pública. El control sobre el cumplimiento de las previsiones de la LOIEMH en este ámbito concreto no ha existido de forma real, las medidas no se acompañaron desde su aprobación de un procedimiento de fiscalización del cumplimiento de dichas medidas. Tan solo, el Real Decreto-ley 18/2017, de 24 de noviembre, introduce una novedosa formulación en relación a informar sobre la diversidad de género del consejo de administración de las sociedades cotizadas: se introduce un nuevo contenido al Informe Anual de Gobierno Corporativo que habrá de remitirse a la CNMV (arts. 540.1 y 540.4.6 LSC) ${ }^{31}$. Sin embargo, un informe contrario a los objetivos de la LOIEMH no encontrará reproche alguno por parte del ordenamiento jurídico y, en suma, no tendrán una respuesta sancionadora. Nuestro sistema, por tanto, reduce a la voluntariedad empresarial la consecución de una presencia equilibrada en el consejo. Es tan potestativa que, a pesar de que la LOIEMH introduce un ambicioso horizonte en favor de la diversidad de género y, por tanto, en favor de la igualdad real entre mujeres y hombres, la reforma introducida en relación a facilitar dicha información a la CNMV, posibilita justificar el incumplimiento de los arts. 54 y 75 LOIEMH si las empresas motivan el incumplimiento de dichas previsiones, además, si no lo justificaran, no encontrarían reproche alguno, por parte del ordenamiento. Por tanto, todas estas previsiones han supuesto, en la práctica, un refuerzo a la responsabilidad social empresarial pero no puede decirse lo mismo en relación a la consecución de una sociedad más igualitaria y más democrática.

Sin duda, debe tenderse a la obligación vinculante y sancionable. Por consiguiente, debe extenderse a otro tipo de sociedades mercantiles, más allá de las sociedades cotizadas que, sin embargo, por su relevancia en el haz de relaciones sociales y económicas que rigen las sociedades modernas, deberían seguir siendo un destinatario primario. El control sobre la retribución de los consejeros y consejeras de las compañías debe ser también fiscalizable de algún modo para poder apreciar sesgos a eliminar para una completa superación de la brecha retributiva por razón de género. Sin perjuicio de que se reduzca

${ }^{30}$ Consultado en: https://civio.es/quien-manda/2018/02/05/el-80-de-las-empresas-publicas-ignora-la-ley-deigualdad-en-sus-consejos-de-administracion/ (fecha: 27 de noviembre de 2019).

${ }^{31}$ En concreto, conforme al art. 540.1.6 LSC, se trata de una descripción de la política de diversidad aplicada en relación con el consejo de administración, en concreto, en lo que respecta al el género; incluyendo sus objetivos, las medidas adoptadas, la forma en la que se han aplicado, en particular, los procedimientos para procurar incluir en el consejo de administración un número de mujeres que permita alcanzar una presencia equilibrada de mujeres y hombres y los resultados en el período de presentación de informes, así como las medidas que, en su caso, hubiera acordado respecto de estas cuestiones la comisión de nombramientos (por ejemplo, retribuciones de los consejeros). También tendrá un contenido de información al accionariado en relación a estas cuestiones y expresar en el informe una razón clara y motivada sobre su incumplimiento. 
al ámbito de los consejeros no ejecutivos, para lograr un equilibrio entre los intereses del Estado de Derecho y de las sociedades mercantiles, protegiendo su poder de auto organización emanado de la libertad de empresa, puede irse pensando en adoptar otro tipo de medidas complementarias de las cuotas, quizá informativas, en relación a la progresión de las mujeres en el management empresarial y ver el papel real que van asumiendo en las mismas.

\section{Conclusiones: una propuesta de lege ferenda}

Ante la lentitud e inobservancia en el cumplimiento de las previsiones de la LOIEMH y la todavía inalcanzable composición equilibrada del consejo de administración de las grandes compañías, el Estado Social y Democrático de Derecho debe dar una respuesta para superar este reto. Por todas las implicaciones que representan las sociedades mercantiles cotizadas y su papel en la adopción de las políticas públicas, las grandes compañías deben ser sometidas a un régimen jurídico de incorporación obligatoria de mujeres en sus esferas de administración y gestión, de tal forma que se incorpore una democracia paritaria y plenamente participativa dentro de las estructuras corporativas de las empresas. Por ende, se propone la adopción de una concreta medida de acción positiva: un sistema de cuotas obligatorias para reformular el art. 75 LOIEMH y el art. 529 bis.2 LSC, abandonando el "procurar" y el "velar" por "observar" o "cumplir", en aras de la igualdad de hombres y mujeres en tanto medida de acción positiva (arts. 9.2 y $14 \mathrm{CE}$ ).

El primero debiera adoptar un carácter vinculante y algún tipo de previsión sancionadora coercitiva de cuantía significativa, que no solo castigue la inobservancia del precepto sino despliegue una función disuasoria al respecto. Por todo lo expuesto, obligar a las empresas cotizadas a someter el nombramiento de su consejo de administración a un canon paritario que puede seguir articulado en torno a las previsiones de la D.A. 1a LOIE$\mathrm{MH}$, donde la CNMV puede ser un protagonista fiscalizador de su cumplimiento, no supondría una medida injustificada desde el punto de vista constitucional. Solo así, el Estado puede promover una igualdad en todos los ámbitos de la sociedad y, especialmente, en la faceta social y económica de las personas, desplegando así su inspiración democrática y social, salvaguardando la igualdad efectiva entre mujeres y hombres en tanto elemento consustancial a su nacimiento.

Sin perjuicio de que pueda extenderse a otras empresas, debemos centrarnos en su acotamiento a las sociedades cotizadas en tanto cúspide del sistema empresarial y bancario español, quedando a salvo el principio plutocrático que inspira la conformación de la voluntad societaria y, quizá, reducida al ámbito de los consejeros no ejecutivos para mermar el menoscabo al poder de auto organización empresarial. Esto es, no afectando el desenvolvimiento diario de la gestión empresarial, más allá de la mera administración en sede del consejo.

En suma, para asegurarse un cumplimiento real de la medida y no la observancia de un mero formalismo (e incorporar a mujeres sin funciones y autonomía en el consejo), por 
el respeto que debe guardarse a los principios de mérito y capacidad (que deben ser superados en la eventual selección de los miembros del consejo de administración); debe optarse por desarrollar un sistema de control público ex post sobre dichos nombramientos, que la CNMV podría asumir como lo hace ya en relación al Informe de Gobierno Corporativo. Así, sin perjuicio de adoptar un régimen transitorio, tendría sentido seguir exigiendo una motivación acerca de apartarse de la obligación de adoptar una presencia equilibrada en sede del consejo de administración, aunque los argumentos aducidos por la empresa a la CNMV debieran comprobarse y, en relación a una labor de averiguación precedente, decidir sobre un régimen sancionador ad hoc. Sin olvidar que el mantenimiento de estas medidas habría de mantenerse en el tiempo hasta que se hubiera normalizado la composición equitativa de los consejos de administración, si es que llega a materializarse.

\section{Bibliografía}

ALEXY, ROBERT. (2007). Derechos sociales y ponderación. Madrid: Fundación Coloquio Jurídico Europeo.

ARAGÓN REYES, MANUEL. (1995). Libertades económicas y Estado Social. Madrid: Mc Graw-Hill.

BALAGUER CALLEJÓN, MARÍA LUISA. (2010). Mujer y constitución: la construcción jurídica del género. Madrid: Cátedra.

BELTRÁN, JOSÉ LUIS; IBAÑEZ JIMÉNEZ, JAVIER WENCESLAO y SÁNCHEZ GRAELLS (coords.). (2012) Fundamentos de Derecho Empresarial. Tomo 2. Madrid: Civitas.

BINGHAM, TOM. (2018). El Estado de Derecho. Ciudad de México: Tirant lo Blanch.

CHAMORRO DOMÍNGUEZ, MARÍA CONCEPCIÓN. (2019). Diversidad de género en los consejos de administración de las sociedades cotizadas españolas. A propósito de la publicación de la CNMV de datos sobre la presencia de mujeres en consejos de administración y alta dirección de sociedades cotizadas españolas. En Derecho de Sociedades, 55.

CIDONCHA MARTÍN, ANTONIO. (2006). La libertad de empresa. Madrid: Civitas.

FIGUERUELO BURRIEZA, ÁNGELA. (2014). Igualdad de género en la toma de decisiones; sobre la composición equilibrada de los consejos de administración de las grandes empresas. En Igualdad y democracia: el género como categoría de análisis jurídico: estudios en homenaje a la profesora Julia Sevilla. Valencia: Cortes Valencianas.

GALGANO, FRANCESCO. (1981). Historia del Derecho Mercantil. Barcelona: Laia.

GARCÍA DE ENTERRÍA, EDUARDO. (1981). La Constitución como norma y el Tribunal Constitucional. Madrid: Civitas.

GARCÍA CRUCES, JOSÉ ANTONIO. (2016). Derecho de sociedades mercantiles. Valencia: Tirant lo Blanch.

HESSE, KONRAD. (1995). Derecho Constitucional y Derecho Privado. Madrid: Civitas.

GARCÍA MEXÍA, PABLO. (2008). Ética y gobernanza. Estado y sociedad ante el abuso de poder. Valencia: Tirant lo Blanch. 
GIL ECHEVERRY, JORGE HERNÁN. (2012). Derecho societario contemporáneo. Bogotá: Legis. HUERTA VIESCA, MARÍA ISABEL. (2009). Las mujeres en la nueva regulación de los consejos de administración de las sociedades mercantiles españolas. Navarra: Aranzadi.

LOUSADA AROCHENA, FERNANDO. (2004). El informe sobre el impacto de género en la elaboración normativa. En Aequalitas: Revista jurídica de igualdad de oportunidades entre mujeres y hombres, 15, 39-46.

MORALES, LETICIA. (2015). Derechos sociales constitucionales y democracia. Madrid: Marcial Pons.

NUÑO GÓMEZ, LAURA. (2009). El origen de las políticas de género: la evolución legislativa y las políticas de igualdad en el estado español. En María Dolores Cancio Alvarez, Enrique Álvarez Conde, Ángela Figueruelo Burrieza y Laura Nuño Gómez (coords.), Estudios interdisciplinares sobre igualdad (pp. 277-316). Madrid: Iustel.

PAREJO ALFONSO, LUCIANO. (1990). Constitución y valores del ordenamiento. Madrid: Editorial Centro de Estudios Ramón Areces.

PÉREZ ESCALONA, SUSANA. (2007). La asociación y el derecho de sociedades: una revisión en clave contractual. Madrid: Civitas.

PETIT, CARLOS. (2016). Historia del Derecho Mercantil. Madrid: Marcial Pons.

PRIETO SANCHÍS, LUIS. (2013). El constitucionalismo de los derechos. Madrid: Trotta.

REY MARTÍNEZ, FERNANDO. (1994). La propiedad privada en la Constitución Española. Madrid: Centro de Estudios Políticos y Constitucionales.

ROBLES MORCHÓN, GREGORIO. (1992). Los derechos fundamentales y la ética en la sociedad actual. Madrid: Civitas.

RODRIGUES CANOTILHO, MARIANA. (2017). El principio de igualdad en el derecho constitucional europeo. Navarra: Aranzadi.

SALAZAR BENÍTEZ, OCTAVIO (2014). El reto de la democracia paritaria. En Víctor Manuel Cuesta López y Dulce María Santana Vega (coords.), Estado de Derecho y discriminación por razón de género, orientación e identidad sexual (pp. 89-108). Navarra: Aranzadi.

SEVILLA MERINO, JULIA. (2003). Democracia paritaria y Constitución. En AA.VV., Seminario "Balance y Perspectivas de los Estudios de las Mujeres y del Género" (pp. 28-58). Madrid: Ministerio de Trabajo e Inmigración, Instituto de la Mujer.

SØRENSEN, GEORG. (2010). La transformación del Estado. Más allá del mito del repliegue. Valencia: Tirant lo Blanch.

TOMILLO URBINA, JORGE. (2016). La sociedad como categoría general. En Julio Álvarez Rubio (coord.), Derecho de Sociedades. Madrid: Dikinson.

VENTURA FRANCH, ASUNCIÓN y GARCÍA CAMPÁ, SANTIAGO (dirs.). (2018) El derecho a la igualdad efectiva de mujeres y hombres. Una evaluación del primer decenio de la Ley Orgánica 3/2007. Navarra: Aranzadi.

ZINTI, REINHARD. (1993). Neoliberalismo y Estado social. En Doxa 13, 33-47. 